\section{UKCPR}

University of Kentucky

Center for

Poverty Research

\section{Discussion Paper Series}

DP 2012-08

ISSN: 1936-9379

\title{
Food Insecurity Across the First Five Years: Triggers of Onset and Exit
}

\author{
Alison Jacknowitz \\ Department of Public Administration and Policy \\ American University \\ Taryn W. Morrissey \\ Department of Administration and Policy \\ American University
}

October, 2012

\section{Preferred citation}

Jacknowitz, A. \& Morrissey, T. Food Insecurity across the First Five Years: Triggers of Onset and Exit. University of Kentucky Center for Poverty Research Discussion Paper Series, DP2012-08. Retrieved [Date] from http://www.ukcpr.org/Publications/DP2012-08.pdf.

Author correspondence

Alison Jacknowitz, 4400 Massachusetts Avenue, NW, Washington, DC, 20016;

Email: jacknowi@american.edu; Phone: (202)885-2137. 
FOOD INSECURITY ACROSS THE FIRST FIVE YEARS: TRIGGERS OF ONSET AND EXIT*

\author{
Alison Jacknowitz, Taryn W. Morrissey, and Andrew Brannegan
}

October 25, 2012

\footnotetext{
* This project was supported with a grant from the University of Kentucky Center for Poverty Research (UKCPR) through funding by the U.S. Department of Agriculture, Food and Nutrition Service, contract number AG-3198-B-10-0028. The opinions and conclusions expressed herein are solely those of the author(s) and should not be construed as representing the opinions or policies of the UKCPR or any agency of the Federal Government. Katie Vinopal and Alexander Testa provided excellent research assistance. Craig Gundersen, James Ziliak, and participants at the National Association for Welfare Research and Statistics Annual Conference and UKCPR grants conferences provided helpful comments. Please direct correspondence to Alison Jacknowitz at American University, 4400 Massachusetts Avenue, NW, Washington, DC, 20016 or jacknowi@american.edu.
} 


\section{FOOD INSECURITY ACROSS THE FIRST FIVE YEARS: TRIGGERS OF ONSET AND EXIT: ABSTRACT}

Very low food security among young children is associated with developmental deficiencies. However, little is known about the factors that predict entry into or exit from very low food security during early childhood. This study seeks to: (1) Understand the triggers that explain movements into or out of very low food security among children from birth to age five; (2) Examine the first aim using different definitions of food insecurity. The analysis relies on the Early Childhood Longitudinal Study-Birth Cohort (ECLS-B), a longitudinal, nationally representative dataset of approximately 10,700 children, to estimate linear probability models. Results suggest that residential moves and declines in maternal or child health are associated with transitioning into food insecurity, whereas increases in the number of adults in the household are associated with exits from food insecurity. Changes in income and maternal depression are associated with both entrances and exits. These findings are robust to different definitions of food insecurity and model specifications. Findings can help nutrition assistance programs target parents and their children for assistance and information on coping strategies when they are most at risk of experiencing food insecurity. 


\section{FOOD INSECURITY ACROSS THE FIRST FIVE YEARS: TRIGGERS OF ONSET AND EXIT: EXECUTIVE SUMMARY}

In 2011, 1.0 percent of households with children experienced very low food security among children, indicating that children themselves were hungry or went without food (Coleman-Jensen et al., 2012). Although the prevalence of very low food security among children can be viewed as low, the short- and long-term consequences cannot be overlooked, particularly during early childhood. Still, little is known about the patterns of very low food security among young children. This study addresses this gap in the literature by examining the predictors of the entry into and exit from very low food security over the first five years of life. Specifically, the two primary research aims of this study are the following: (1) Understand the triggers or shocks that explain movements into or out of very low food security among children from birth to age five, and (2) Examine the first aim using different definitions of food insecurity, including low and very low food security among children, very low food security among adults and children, and low and very low food security among adults and children.

The analysis relies on data from the Early Childhood Longitudinal Study-Birth Cohort (ECLS-B), a longitudinal, nationally representative dataset of approximately 10,700 births in 2001, which followed children from birth to kindergarten entry. Data used in this study were

collected when children were nine months, two years, four years, and at kindergarten entry — the first four of the five waves of data. Information on food insecurity from the 18-item Core Food Security Module (CFSM) and a rich set of variables on child, maternal, and household characteristics were collected at each time point. The ECLS-B also includes zip codes, which allows the data to be merged with county-level contextual variables such as the rates of poverty, unemployment, and participation in food assistance programs. 
Using an analysis sample of 18,950 transitions between waves of data, this study tests the hypothesis that events or changes in child, maternal, and household circumstances affect the likelihood of entry into and exit from very low food security among children (Aim 1) by estimating two linear probability models. In the first model, which investigates the entry into very low food security, children who transitioned into very low food security between waves of data are compared to those who were food secure in both waves. In the second model, which examines the exit from food insecurity, children who transitioned out of very low food security between waves of data are compared to children who experienced very low food security in both waves. For Aim 2, these same models were estimated using different definitions of food insecurity.

\section{Graph 1. Percentage of Transitions Entering and Exiting Food Insecurity}

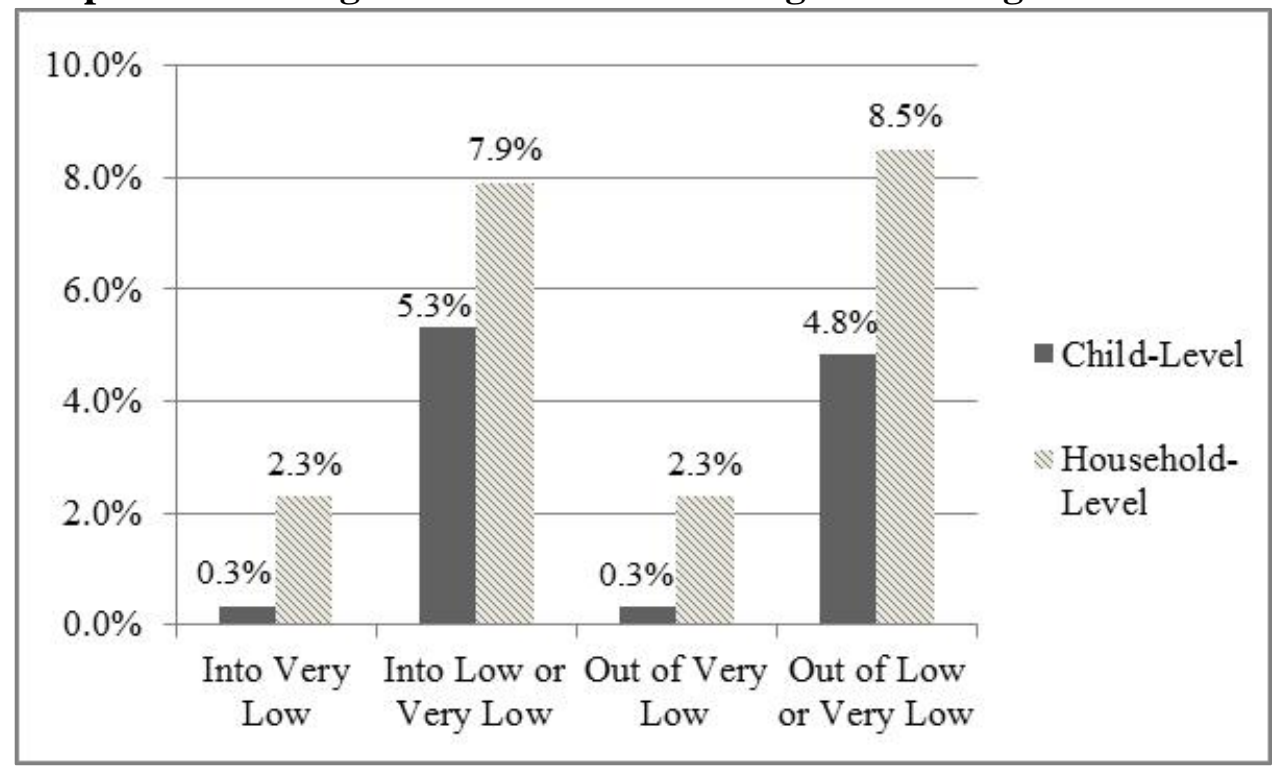

Note: Sample size is 18,950 transitions.

Descriptive analysis in Graph 1 provides an overview of the percent of the baseline sample experiencing transitions in food insecurity status. Not surprisingly, a very small percentage of the transitions represent children moving into very low food security or out of very low food security. As expected, a larger percentage of transitions involve movements into low or 
very low food security or out of low or very low food security. By comparison, household-level food security status changed more often in the transitions between waves than child-level food security.

Regression results suggest that residential moves and declines in maternal or child health are associated with transitioning into food insecurity, whereas increases in the number of adults in the household are associated with exits from food insecurity. Changes in income and maternal depression are associated with both entrances and exits. These findings are robust to different definitions of food insecurity and model specifications. Findings can help nutrition assistance programs target parents and their children for assistance and information on coping strategies when they are most at risk of experiencing food insecurity. 


\section{INTRODUCTION}

In 2011, 14.9 percent of households in the United States were classified as food insecure (Coleman-Jensen et al., 2012), defined as "having limited or uncertain availability of food, or limited or uncertain ability to acquire acceptable foods in socially acceptable ways”1 (Skalicky et al., 2006). Of these food-insecure households, more than one-third (5.7\% of all households in the U.S.) experienced very low food security (Coleman-Jensen et al., 2012). Very low food security is more severe than low food security, and can entail reduced food intake and disrupted eating patterns. While children are typically protected from food need, 9.0 percent of households with children were classified as experiencing low food security among children and 1.0 percent of all households with children experienced very low food security among children, meaning that children themselves did not have adequate food (Coleman-Jensen et al., 2012).

Although the prevalence of food insecurity among children can be viewed as low, the consequences cannot be overlooked, especially with regard to food insecurity experienced during the early childhood period. Even when children themselves do not experience hunger, their parents' experiences of food insecurity pose serious threats to children’s physical, behavioral, and cognitive development, mediated through parental stress or depression (see Nord [2009] for a comprehensive review of this literature). Young children who live in food-insecure households are more likely to experience fair or poor health (Bronte-Tinkew et al., 2007; Cook et al., 2004; 2006), are more likely to have been hospitalized since birth (Cook et al., 2004; 2006), and exhibit more behavioral problems, including aggressiveness, hyperactivity, depression, and anxiety (Whitaker, Phillips, \& Orzel, 2006) than their counterparts in food-secure households.

\footnotetext{
${ }^{1}$ Food insecurity measures both the quality and quantity of food based on an 18-item scale developed by the USDA. The scale captures experiences at the household level (in the last 12 months), such as running out of food, perceptions that food in a household is of inadequate quality or quantity, and reduced food intake by adults or children, all because of financial constraints (Bickel et al., 2000). The scale assesses food insecurity as "low food security" and "very low food security”. For more information see Coleman-Jensen et al. (2012).
} 
Presumably, the health consequences of directly experiencing food insecurity in terms of lack of food are more severe than the indirect effects via parent stress or other household processes. Furthermore, the health consequences of food insecurity are likely to be more severe when experienced during early childhood, as opposed to older ages, as developmental psychology theory and research emphasize the importance of early experiences for children's physical, cognitive, and social-emotional development (e.g., Bronfenbrenner \& Morris, 1998; Shonkoff \& Phillips, 2000). For example, Shonkoff and Phillips (2000) suggest that nutritional deficiency during infancy can lead to impaired brain development. Because of these consequences, this study focuses on food insecurity directly experienced by children from birth to five years of age.

Despite the severe and long-lasting consequences of food insecurity, little is known about the factors related to child-level food insecurity, especially among young children. This study uses a nationally-representative, longitudinal dataset, the Early Childhood Longitudinal StudyBirth Cohort (ECLS-B), to examine the triggers or shocks that contribute to the onset of and exit from very low food security among young children. Triggers examined include changes in employment, income, household composition, child health, maternal mental and physical health, and residential moves. Specifically, the two primary research aims of this study are.

1) Understand the triggers or shocks that explain movements into or out of very low food security among children from birth to age five.

2) Examine the first aim using different definitions of food insecurity, including low and very low food security among children, very low food security among adults and children, and low and very low food security among adults and children. 
By understanding the triggers of very low food security, food assistance and other public programs can better target resources to serve the families most at risk or most in need; likewise, policies can be improved to build upon identified predictors that help lift children out of food insecurity.

\section{BACKGROUND}

The limited research on the factors related to child-level food insecurity experienced during early childhood, which focuses on children of all ages and uses varying definitions of food insecurity, indicates that household income, employment, and education level, which are indicators of families' social and economic resources, are important predictors. Approximately one-quarter (24.1\%) of U.S. households below the poverty line had food-insecure children (Coleman-Jensen et al., 2012). Households classified as food insecure are less likely to have health insurance (Gundersen \& Gruber, 2001), and food-insecure households with children are more likely to be mother-headed, have more children, and average lower education among adults than their food-secure counterparts (Bartfeld \& Dunifon, 2006). In 2007, about half (55\%) of households with food-insecure children had no adult with any education beyond the high school level; among households with children experiencing very low food security, 59 percent had no adult members with more than a high school degree (Nord, 2009). However, employment and higher income do not guarantee food security. More than two-thirds (69\%) of households with children classified as having low food security had one or more persons employed full-time; 62 percent of children with very low food security lived in households with one or more persons employed full-time (Nord, 2009).

While several studies document the correlates of food insecurity, less is known about why children themselves enter or exit food insecurity - that is, what factors, events, or "shocks" trigger the onset of or exit from food insecurity among young children. Understanding these 
factors is important because food insecurity tends to be episodic rather than chronic (ColemanJensen et al., 2012); thus, changes in food insecurity status are likely frequent among young children living in low-resourced families. Further, these predictors of very low food security among young children may be different from those associated with the food insecurity of older children and adults. For example, the effect of maternal depression on school-age children's food insecurity may be mitigated by the receipt of school breakfast or lunch; however, young children, who receive more of their nutritional intake from their families, may be negatively affected by maternal depression as it may impede a mother’s ability to purchase and prepare food.

Relevant to understanding triggers of changes in food insecurity status, poverty research indicates that changes in employment, family composition, parent or child health, and receipt of public programs predict entry or exit from poverty (e.g., Blank, 1997; Chen \& Corak, 2008; Lichter, Qian, \& Melliot, 2006). Indeed, previous research suggests that unexpected losses in income, particularly among low-income families, create budget constraints that render households susceptible to food insecurity (Gundersen \& Gruber, 2001). Similarly, parental job loss, divorce, the birth of a child, or unexpected health expenses may place greater strain on families’ economic resources. Conversely, a parent's entry into the labor force, income increases, marriage or union formation, or improvements in health may help lift children and their families out of food insecurity.

\section{METHODLOGY}

\section{ECLS-B}

The ECLS-B is a longitudinal dataset collected by the National Center for Education Statistics (NCES). The baseline sample of approximately 10,700 children was designed to be nationally representative of children born in the U.S. in 2001 with an over-sample of Asian and 
American Indian children, twins, and low and very low birthweight children. ${ }^{2}$ The ECLS-B followed children from birth through kindergarten with data collection occurring when the child was 9 months of age (2001-02), 2 years of age (2003-04), approximately 4 years of age (200506, also known as the preschool wave), and at two waves at kindergarten entry (2006-08). ${ }^{3}$ The 9-month data collection also includes variables from infants' birth certificates. This research relies on data from the first four waves of the ECLS-B, thus excluding information from the smaller, second kindergarten wave of data.

Given the broad motivations of the ECLS-B, these data are rich and appropriate for this study. ${ }^{4}$ The ECLS-B is the only longitudinal dataset of young children that contains the full 18item U.S. Department of Agriculture (USDA) Core Food Security Module (CFSM) in every wave of data collection. The use of a dataset that includes the CFSM allows for comparisons of results with other studies and an exploration of the research aims at multiple levels of food insecurity. The very low food security rate among children generated using the first wave of data from the ECLS-B is remarkably similar to that generated using the Current Population Survey (CPS) (0.5 percent from the ECLS-B and 0.6 percent from the CPS) (Coleman-Jensen et al., 2012). ${ }^{5}$ For these reasons, the ECLS-B data are preferred for this analysis over data from the Survey of Income and Program Participation (SIPP) and the Fragile Families and Child Wellbeing Study. The ECLS-B also contains a rich set of variables on child, maternal, and household characteristics. Finally, the ECLS-B includes zip codes, which facilitates the merger

\footnotetext{
${ }^{2}$ The reported sample sizes have been rounded to the nearest 50, per NCES regulations regarding disclosure of restricted-use data.

${ }^{3}$ In the fall of 2006, information was collected from all participating children, approximately 75 percent of whom were in kindergarten or higher. In the fall of 2007, data were collected from the remaining 25 percent of participating children who were first entering or were repeating kindergarten in the 2007-08 school year.

${ }^{4}$ For additional information see the ECLS-B survey instruments at http://nces.ed.gov/ecls/Birth.asp.

${ }^{5}$ While the ECLS-B and CPS very low food security rates among children may not be directly comparable because of the age of children studied, the closeness of the two rates is suggestive of the validity of the ECLS-B.
} 
and analysis of county-level contextual variables such as the rates of poverty, unemployment, and participation in food assistance programs.

\section{Empirical Strategy}

This paper tests the hypothesis that events or changes in child, maternal, and household circumstances affect the likelihood of entry into and exit from very low food security among children (Aim 1) by estimating two linear probability models that are represented by Equation 1.

$$
Y_{i t}=B_{0}+B_{1} X_{i t}+B_{2} Z_{i}+\varepsilon_{i t}
$$

In Equation 1, $Y_{i t}$ captures two dependent variables for child $i$ in transition $t$. Given that the dependent variables are binary, linear probability models are appropriate. ${ }^{6}$ Separate regression models predicting entry into and exit from very low food security are estimated instead of one regression model with child fixed-effects to determine if factors that influence entry into and exit from very low food security are different as suggested by the finding in Heflin and Butler (in press) that different factors predict entry into and exit from material hardship. Hazard models are not used because children can move in and out of states over the four waves of data collection and the data are not collected at consistent intervals.

The dependent variables capture experiences of food insecurity over the past 12 months using the 18-question CFSM. Ten questions correspond to the experiences of the household and adults, while the remaining questions focus on the children. Questions ask respondents about their experiences over the past 12 months regarding their food purchases, consumption, and concerns (e.g., whether they were worried their food would run out before they had money to buy more, whether they cut the size of or skip their own or their children's meals because there wasn’t enough money to buy food). From these questions, a raw score, a scale score, and a categorical measure of food security at the following three levels are generated: household food

\footnotetext{
${ }^{6}$ Results (available upon request) from logit models are qualitatively similar to those presented in the paper.
} 
security, adult food security, and child food security. ${ }^{7}$ For each level of food security, a household, adult, or child is classified as being food secure, having low food security, or having very low food security. ${ }^{8}$ To address the study aims, this analysis relies on the food security categorical variables for children and households where child-level food insecurity captures whether a child in the household is experiencing the condition and household-level captures whether any member of the household (adult and/or child) is experiencing the condition.

The first dependent variable is a binary variable for which those who enter very low food security (from any food security status) are coded as "1" and those who are food secure or have low food security in both waves are coded as "0". Essentially, the entry model includes only those who were food secure or had low food security in the first wave of the transition. Those transitions that experienced very low food security in the subsequent wave were coded "1" and those that remained low food secure or food secure were a "0". The second dependent variable is a binary variable representing those who exit from very low food security (to any food security status), who are coded as " 1 ", compared to those who experience very low food security in both waves and are coded as " 0 ". Therefore, the exit model includes only those transitions that experienced very low food security in the first wave. Those transitions that remained very low food secure in the subsequent wave were coded as a " 0 " and those that became food secure or experienced low food security were coded as a "1". See Appendix Table 1 for a detailed explanation of these variables and other variables used in the analysis.

The vector $X$ includes factors that trigger entry into very low food security or exit from

\footnotetext{
${ }^{7}$ The raw scores are the number of questions answered affirmatively (i.e., yes; often or sometimes; almost every month or some months but not every month). The scale score is a Rasch transformation of the raw score. See Ohls, Radbill, and Schirm (2001) for more information. The household-level variables are calculated according to Bickel et al. (2000), and the child-level variables are calculated according to Nord and Bickel (2002).

${ }^{8}$ Note that the ECLS-B refers to these categories as food secure, food insecure without hunger, and food insecure with hunger. The above terms are used in accordance with the National Academies of Sciences recommendation (Wunderlich \& Norwood, 2006).
} 
very low food security among children from birth to age five, focusing on multiple levels of children's environments. The analyses focus on child-, maternal-, and household-level factors that change, with an emphasis on those identified as influencing transitions into and out of poverty. Specifically, triggers that capture a change in resources, resources needed, or the ability to manage resources are examined. Changes in these characteristics are calculated for the transitions between each of the four waves of data collection used in this study (9 months and 2, 4, and 5 years). Although there are a few years between each wave of data collection, previous research demonstrates that economic and household changes can have long-lasting impacts on food security (e.g., Gundersen \& Gruber, 2001). When predicting entry into very low food security, we include "negative events" experienced by the household as predictors for entry into very low food security as we hypothesize that negative events or changes in circumstances such as job loss will predict the onset of very low food security. Conversely, when examining exit from very low food security, "positive events" are included in the models. Three of the events in the models (change in employment status, health, and depression) are asked of the survey respondent, but are attributed to the mother in this analysis because 96.5 percent of the interviews were conducted with the biological or adoptive mothers of the sampled children.

The first trigger examines change in maternal employment status, as reported by survey respondents, with the following four variables representing this event: became employed, became unemployed and exited the labor force, became unemployed and remained in the labor force, and employment status remained the same. To code these variables, the mother's selfreported job status in one wave is compared with that in the next wave, and binary variables representing the change are generated. Moving to unemployment is divided into two categories to distinguish between those who are not looking for work (e.g., stay-at-home mothers) and those 
who are. Becoming employed is considered a positive event, as it represents the introduction of more resources, and becoming unemployed is considered a negative event as it results in a household having fewer resources.

The next triggers capture how changes in household composition influence the entry into and exit from very low food security: a change in the number of adults aged 18 years or older in the household, and a change in the number of children under 18 years living in the household, as reported by respondents at each wave. Both of these events are represented by the following three binary variables: number increased, number decreased, and number remained the same. An increase in the number of adults and decrease in the number of children is considered a positive event as an additional adult could represent more resources for the family, whereas an additional child will consume more resources. In contrast, decreases in the number of adults and increases in the number of children are considered negative events.

Next, how changes in household income influence food security is investigated. At each wave, respondents reported the bracket that included their total household income, capturing resources for all adults. Brackets were measured in $\$ 5,000$ intervals for income under $\$ 40,000$ (e.g., $\$ 0-\$ 5,000$, $\$ 5,001-\$ 10,000$, and $\$ 10,001-\$ 15,000$ ) and were much larger for higher incomes (e.g., $\$ 75,001-\$ 100,000$, $\$ 100,001-\$ 200,000$ and $\$ 200,001$ or more). Like changes in household composition, this trigger is coded as three binary variables: income increased, decreased, or remained the same. Increasing income is considered a positive event and decreasing income is considered a negative event. This income variable is also used to approximate the household's FPL level at each wave.

Also examined is whether improvements or declines in the mother's or child's physical health over time predicts the onset of or exit from very low food security. The predictor is 
derived from the question asking the respondent to rate her general health and her child's general health as excellent, very good, good, fair, or poor. Changes between waves in both of these general health variables are coded as health improved, health declined, or health remained the same. An improvement in health is considered a positive event, as an improvement in maternal health facilitates maternal employment and an improvement in child health requires less household resources. In contrast, a decline in health is considered a negative event.

Related to health, whether maternal depression triggers entry into or exit from very low food security is investigated. Maternal depression was measured from mothers' responses to a modified version of the Center for Epidemiologic Studies Depression Scale (CES-D; Radloff, 1977) at 9 months, preschool, and kindergarten entry and using the Depression Scale of the Composite International Diagnostic Interview Short Form (CIDI-SF; Kessler et al., 2003) at 2 years. Consistent with other research using the modified 12-item CES-D, we considered those with moderate or severe symptoms (a raw score greater than 9) to be depressed. The CIDI-SF was originally created for the National Health Interview Survey (NHIS) using questions from the full CIDI, an instrument used internationally in cross-cultural epidemiological studies of mental disorders. Only the depression questions were included in the ECLS-B. Whereas the CIDI-SF asks about the participants' experience over the previous 12 months, the questions were revised to ask about the period since the previous interview in the ECLS-B. The CIDI-SF uses a stembranch logic in which individuals are first asked 3 stem questions pertaining to their feelings of dysphoria and its persistence. If respondents deny symptoms or the persistence of symptoms, they are considered as not a having major depressive disorder; if an individual responds affirmatively to at least one stem question, they are asked 7 additional branch questions about other symptoms including losing interest, difficulty sleeping, changes in weight, trouble 
concentrating, feeling down, and thoughts about death. Consistent with previous studies using the CIDI-SF, mothers who reported an affirmative answer to one of the stem questions were considered moderately or severely depressed. Becoming depressed is considered a negative event, as depressed mothers may need more resources, be less able to manage resources, and be less likely to be employed. Recovering from depression is considered a positive event.

Finally, whether household residential moves predict changes in children's food security is tested. This variable is based on a question asking the respondent if they moved since the last interview, and is coded as a household moved residences compared to a household did not move. While moving is a stressful event for children, if a child moves to a better neighborhood with better schools, lower poverty, improved access to food, or a lower crime rate, it has positive implications and thus predicts exit from food insecurity. Hence, the effect of moving on entry into and exit from very low food security is ambiguous.

In addition to the triggers explained above, regression models include additional, childlevel variables $(Z)$ including binary variables representing that the child is female, race/ethnicity, and part of a multiple birth. Child race/ethnicity is coded as a series of binary variables including child is non-Hispanic White (reference), child is non-Hispanic Black, child is Hispanic, and child is other race/ethnicity. An indicator variable for whether the child is part of a multiple birth is included as the ECLS-B oversamples twins and being part of a multiple birth may influence transitions into and out of very low food security. Finally, binary variables for each transition in the model to capture age and year effects of the child are included, with the final transition (between waves 3 and 4) being the reference category.

Descriptive statistics and regression estimates from the linear probability models are not weighted because the ECLS-B dataset is transformed with the unit of analysis being the 
transition between waves, and an appropriate weight is not provided. Standard errors of the regression coefficients are adjusted to account for multiple observations for the same child. For Aim 2, the Aim 1 analyses are re-estimated using the following three additional definitions of food insecurity: very low or low food security among children, very low food security among children and adults, and very low or low food security among children and adults.

\section{Analysis Sample}

The baseline analysis sample represents 7,850 children who resided in a household with income at or below 300 percent of the Federal Poverty Level (FPL; $\$ 60,000$ for a family of 4 in 2006) at some point during the first four waves. ${ }^{9}$ In other words, if household income at any wave is at or below 300 percent of the FPL, then the child remains in the sample. In contrast, if a child resides in a household with income above 300 percent of FPL for every wave, then the child is excluded from the analysis. In the case of missing income information, if all non-missing income values are above 300 percent of FPL, the child is excluded from the sample; otherwise, the child is included. A large number of children $(4,050)$ with missing data in at least one of the first four waves remain in the sample because low-income households tend to be less likely to report income and to preserve sample size. ${ }^{10}$ The analysis sample is broadly defined because many food-insecure children live well above the poverty line; 0.2 percent of households above 185 percent of the FPL contain children who are considered as having very low food security, and 8.0 percent of households with children above 185 percent of the FPL contain adults or children classified as food insecure (Coleman-Jensen et al., 2012). In total, 2,850 children are excluded from the sample because they do not meet the income-related criteria.

\footnotetext{
${ }^{9}$ Income and household size from the ECLS-B and Census Bureau thresholds are used to determine whether a household is at or below 300 percent of the FPL. Because the ECLS-B provides income ranges, each child is assigned the midpoint of the range. This midpoint is compared to three times the FPL based on household size for the first year of each wave.

${ }^{10}$ Results (available upon request) excluding these children missing income are qualitatively similar to those presented.
} 
Given that our research questions seek to identify the predictors of entry into and exit from food insecurity, the unit of analysis is the transition of a sampled child from one wave to the next. With no missing data, each child would have three transitions, between each of the four waves. However, because of missing data, the sample is an unbalanced panel with each child having between one and three transitions in the study. The baseline analysis sample is composed of 18,950 transitions meeting the following non-income related criteria with the number of transitions dropped per criterion in parentheses. The first criterion involves dropping transitions that included missing values for independent variables in the analysis (200). The five independent variables (change of residence, change in employment, change in child health, change in maternal health, and child race) for which transitions are dropped each had less than 100 missing values. For independent variables with more than 100 missing values (change in income, change in maternal depression), missing indicators are created and included in the regressions. The next criterion for which transitions are dropped was if household-level or childlevel food security scores are missing for either wave of the transition $(4,400)$. While the baseline analysis sample includes all transitions that are included in any of the entry or exit analyses (18,950 transitions), the regression analysis sample size varies by the dependent variable, and represents a subsample of the total 18,950 transitions.

Graph 1 provides an overview of the percent of the baseline analysis sample experiencing transitions in food insecurity status. ${ }^{11}$ Not surprisingly, a very small percentage $(0.3 \%)$ of the transitions are children moving into very low food security or out of very low food security. As expected, a larger percentage of transitions involve movements into low or very low food security (5.3\%) or out of low or very low food security (4.8\%). Turning to transitions involving

\footnotetext{
${ }^{11}$ Because these statistics are not weighted, the reader should be cautious in interpreting the findings as nationally representative.
} 
all household members, a large percentage of transitions involve movement into and out of the different categories of food insecurity. Among all transitions, 2.3 percent move into and out of very low food security among all household members. Examining very low or low food security among all household members, 7.9 percent of transitions enter this state and 8.5 percent exit.

Table 1 shows the share of transitions experiencing the positive and negative triggers. Many of our transitions involve a change in residence (41.4\%). Other frequently occurring events involve changes in income, with 43.8 percent of transitions experiencing an increase in income and 31.1 percent having a decrease in income. Additionally, a large percentage of transitions undergo a change in the mother's or child's health status. Twenty-four percent of transitions include an improvement in maternal health; 29.0 percent experience a decline in health; 24.4 percent experience declines in a child's health; and 22.1 percent involve improvements. While changes in the other triggers examined occur less frequently, variation still exists.

Table 1 also provides the demographic characteristics of the baseline analysis sample. Nearly 37 percent of transitions represent children who are non-Hispanic White, 19.2 percent non-Hispanic Black, and 24.0 percent are Hispanic. There is an equal share of males and females in the analysis sample. Given the ECLS-B oversamples twins, it is not surprising that 15.4 percent of transitions are part of a multiple birth.

\section{RESULTS}

\section{Descriptive Statistics}

Tables 2A and 2B describe characteristics of children who entered into and exited from very low food security themselves, and who resided in households who entered into and exited from very low food security, respectively. Because the triggers for movement into and out of very low food security among children and very low food security among all members of the 
household follow similar patterns, the results are discussed together. Compared to the full sample, becoming unemployed, experiencing a decline in income, and experiencing a decrease in the number of adults in the household between data collection waves are more common among those who moved into very low food security. A decline in both child and maternal health are associated with moving into food insecurity along with maternal depression. Finally, a change in residence is associated with moving into food insecurity. The opposing set of triggers (i.e., the opposite or positive changes in these variables) predict exits from food insecurity, with a couple of notable exceptions: a decrease in the number of children and an increase in the number of adults in the household each predict exits from food insecurity.

\section{Regression Analysis}

Addressing Aims 1 and 2, Table 3 shows results from linear probability models predicting entrance into different levels and definitions of food insecurity. The results in Column 1 address the onset of very low food security at the child-level. Triggers that predict this transition include maternal health declines, the onset of maternal depression, and a change in residence. Turning to the models predicting entry into other forms of food insecurity (Columns 2 through 4), a decrease in income, the onset of maternal depression, and a change in residence consistently predict the onset of food insecurity. Interestingly, maternal health declines are only associated with movement into very low food security at the child- and household-level, although the coefficients are small in magnitude. Other triggers that appear to be important in predicting movement into low or very low food security among the household include a decrease in the number of adults, child health declines, and becoming unemployed and remaining in the labor force. It is possible that these factors are important in predicting movement into very low food security among children, in particular, but the sample size of children experiencing very 
low food security is too small to detect significant effects.

Table 4 provides the results predicting exit from different forms of food insecurity from positive triggers or events. The only trigger that predicts a transition out of very low food security among children is a decrease in the number of children. It is likely that other factors are important in explaining this transition; however, it may be that the sample size is too small to detect significant effects. The sample used in the exit regression is smaller than that of the entry regression because fewer transitions are eligible to move out of very low food security. In the models that predict exit from other definitions of food insecurity (Columns 2 through 4), an increase in the number of adults residing in the household is statistically significant in each model. An increase in income and an exit from maternal depression are also consistently significant in each model. In contrast to the entry models, a change in residence does not predict movement out of food insecurity.

The control variables included in the models are consistent with findings in other studies. Being non-Hispanic Black and Hispanic are associated with movements into and out of food insecurity compared to being non-Hispanic White. Although not as consistent, being an other race/ethnicity is also related to movements into and out of food insecurity.

\section{Additional Analyses}

Maternal depression, an important factor in both entry and exit models, warrants further investigation. Regression results suggest that becoming depressed or recovering from depression predicts movement into or out of food insecurity, respectively. However, these results must be interpreted cautiously, as it is not clear whether maternal depression is leading to food insecurity or mothers are becoming depressed because they are food insecure. Other studies such as Heflin and Ziliak (2008) have used fixed effects models to attempt to estimate a causal effect of 
maternal depression on food insufficiency. However, given the structure of the analysis sample, such models are not possible to run. To further understand the relationship between maternal depression and food insecurity and establish a temporal order between the two variables, a lagged model for maternal depression is estimated, testing whether changes in maternal depression are antecedent or subsequent to changes in food insecurity. The results from these models (available upon request) are similar to the entry models in Table 3, but there is no consistent influence of exiting depression in the previous time period on exiting food insecurity.

Change in residence is also a predictor of entry into food insecurity. To identify the characteristics of moves that correspond with entrance into food insecurity, data were collected on county-level contextual data from various public-use sources, including the Common Core of Data, the Bureau of Labor Statistics, the Small Area Income and Poverty Estimates, and the Census Business Pattern Files for 2001 through 2008. Variables studied include those that may influence a household's ability to obtain food, such as access to grocery stores and community food assistance programs, and those that capture levels of disadvantage in a neighborhood, such as number of households receiving assistance, the poverty rate, number of bars, school district expenditures, and the unemployment rate. However, when comparing the previous and subsequent wave means of county-level characteristics of cross-county movers who enter into food insecurity using t-tests (available upon request), no patterns emerge. It is possible that a residential move captures other factors such as family instability. Another possibility is ample variation in contextual variables does not exist to detect statistically significant results. A reestimation of models testing the effects of moving outside of the county on movement into food insecurity (available upon request) are insignificant, indicating the effects of moves on food insecurity are driven by moves within the county. 
Given that food assistance receipt is intended to mitigate food insecurity, additional analyses (available upon request) are performed examining changes in receipt of food stamps (currently called the Supplemental Nutrition Assistance Program [SNAP]) and the Special Supplemental Nutrition Program for Women, Infants, and Children (WIC) as predictors of entry into and exit from food insecurity ${ }^{12}$. Stopping receipt of SNAP and/or WIC is included in the model predicting entry into food insecurity, while starting receipt is included in the model predicting exit from food insecurity. In the entry model, stopping receipt of food assistance has a negative association with entering food insecurity. Because the measure of food insecurity captures the past year and the measure of food assistance represents receipt between waves of data collection, it is difficult to establish a temporal order. A model including the lagged start of SNAP and/or WIC receipt generated similar results, with exiting food assistance programs negatively influencing entering food insecurity. Starting receipt of food assistance has a mixed association with exiting food insecurity. The model including the lagged start of food assistance replicates these mixed findings.

Many sensitivity analyses are estimated to determine the robustness of the main results. First, models are estimated to determine if the results are sensitive to using the categorical food security variables and examining the predictors of entry into and exit from food insecurity separately. To accomplish this, two models are estimated using the raw food insecurity scale scores at the child- and household-levels as the dependent variables. Further, the positive and negative triggers of food insecurity are jointly included in each model. Table 5 shows that the results from the main models are robust with several exceptions; change of residence and declines in child and maternal health no longer have statistically significant influences on entry

\footnotetext{
${ }^{12}$ SNAP helps low-income households buy food they need for a nutritionally adequate diet. WIC provides food assistance, nutritional counseling, and health and social services referrals to low-income pregnant and post-partum women, infants, and young children.
} 
into food insecurity.

Second, in additional analyses available from the authors, the definition of food insecurity is changed to include those who are marginally food secure. Child-level marginal food security is defined as responding affirmatively to one of eight questions and household-level marginal food security is defined as responding affirmatively to one or two of 18 questions. Finally, the models are estimated among a sample of children in the ECLS-B whose parental respondent reported having a high school degree or less education, to ensure our results are not sensitive to one of the income-based inclusion criteria for the analysis sample. The results for both of these analyses are similar to those generated by the main models in Tables 3 and 4 .

\section{DISCUSSION}

This study investigated the triggers or shocks that explain the onset of and exit from food insecurity among young children. Results suggest that, as hypothesized, changes in income and maternal depression are consistently associated with transitioning into and out of food insecurity in the directions predicted. Declines in maternal and child health and residential moves are associated with entry into food insecurity, whereas increases in the number of adults in the household are associated with exits from food insecurity. These results are robust across different definitions of food insecurity, analysis samples, and model specification. Given that these are common household changes or events experienced by many young children, these findings have important implications for policy and future research.

As expected, changes in family income were consistently associated with changes in child- and household-level food insecurity. Increases in income result in more resources with which to purchase food; conversely, decreases in income lead to a tighter budget constraint. Although many low-income families are food secure, and many higher-income families are food insecure, income and family poverty are major predictors of food insufficiency and insecurity 
(e.g., Alaimo et al., 2001). Interestingly, after controlling for changes in income and maternal mental health, changes in employment status were not strongly related to changes in food insecurity, suggesting that the resources derived from employment, rather than the benefits of employment itself, are important for food insecurity. This result may be a consequence of the limited employment variable, which captures the work status of the respondent, who is typically the mother. Likewise, an increase in the number of adults in the household was important in lifting families out of food insecurity. An increase in the number of adults living in the home, whether they are a spouse, partner, or grandparent, may contribute to household income and, independent of income, may serve as an important source of child care, allowing parents to work or to work longer hours.

Changes in maternal mental health appear particularly important to food insecurity. Building on previous research that has linked maternal depression with food insecurity (e.g., Laraia, Siega-Riz, Gundersen, \& Dole, 2006), this study identified associations between the onset of maternal depression and the onset of food insecurity; in turn, improvements in maternal depressive symptoms are associated with exit from food insecurity. Also consistent with hypotheses, declines in self-reported maternal and child health were related to the onset of food insecurity (although unlike maternal depression, improvements in health were not related to exits from food insecurity). Reductions in health may increase health care needs and expenses, and possibly affect parenting behaviors or parents' time, supplanting the resources typically used to purchase or prepare food. However, it is also possible that the onset of food insecurity leads to reductions in parent and child health. Unfortunately, this study is not able to assess timing or order of changes in mental and physical health and food insecurity or the causal directions of these relationships. Indeed, previous research indicates that the causal relationship between food 
insecurity and depression is bidirectional (Huddleston-Casas, Charnigo, \& Simmons, 2009). More research is needed to better understand the causal relationships between maternal depressive symptoms and child- and household-level food insecurity. Given the negative impact of food insecurity on multiple domains of children's development (e.g., Cummings \& Davies, 1994; Grace, Evindar, \& Stewart, 2003; Hay et al., 2003, Gundersen et al., 2008), and evidence that maternal depression mediates the relationship between food insecurity and some aspects of children's development (Bronte-Tinkew et al., 2007), policies and programs that identify and treat maternal depression and other health problems early may have beneficial impacts on children's long-term health and development.

Interestingly, residential mobility is associated with movement into but not out of food insecurity. Due to data limitations, we could not determine why a family moved - for positive reasons, such as to a bigger home or better school district, or for negative reasons, such as a divorce or home foreclosure. This finding builds on previous research that has primarily focused on the negative associations between residential instability and food security (Nord \& Parker, 2010). In our study, among children who moved counties and entered food insecurity, there were no clear differences in county-level characteristics (including poverty level, employment rate, and median income) between the first wave of the transition and the second. However, these analyses included a relatively small sample of children. Previous research has found that intrastate moves are more highly associated with food insecurity than inter-state moves (Tapogna et al., 2004); similarly, we found that intra-county moves drive the associations between residential moves and food insecurity. Further, earlier work suggests that families classified as high- or middle-income who experience food insecurity are disproportionately more likely to report residential moves, which may indicate that a substantial change in income or job loss occurred 
during the previous year that precipitated the move (Nord \& Brent, 2002). Our analysis sample of children at or below 300 percent FPL may exclude these children.

Several limitations of this research should be acknowledged. First, because the CFSM asks about food insecurity among any child in the household and younger children tend to be protected, the sample child may not be the child experiencing food insecurity, but rather, the respondent may be referring to an older sibling. Second, given that so few children of this age group experience very low food security, it is difficult to detect statistically significant effects for this level of food insecurity. Third, caution should be used in interpreting the coefficients on maternal depression and changes in residence and health, as these changes may be a predictor or consequence of changes in food insecurity. Fourth, our independent and dependent variables were based on reliable, valid measures, but were self-reported; desirability bias or poor memory recall about respondents' food security situation, depressive symptoms, or other conditions could affect the validity of results. Finally, given the relatively long periods of time between data collection waves (e.g., two years between the two-year and preschool waves), we are unable to determine the timing or sequence of changes in family circumstances and food security. For example, we do not know whether an increase in income predated exit from food insecurity, or vice versa. This may underlie our findings regarding changes in public food assistance receipt and the onset of and exit from food insecurity, such that having started receiving food assistance is an indication that a family entered food insecurity, not that receiving food assistance predates food insecurity.

Despite these limitations, these findings have important policy implications. Results will help nutrition assistance programs target parents and their children when they are most at risk of experiencing food insecurity, particularly those experiencing changes in family structure, 
maternal health, or residential mobility. Moreover, findings can help inform programs that provide parents with strategies to cope with food insecurity, particularly strategies that help treat parents’ physical or mental health problems. 


\section{REFERENCES}

Alaimo, K., Olson, C. M., Frongillo, E. A., \& Briefel, R. R. (2001). Food insufficiency, family income, and health in US preschool and school-aged children. American Journal of Public Health, 91(5), 781-786.

Bartfeld, J., \& Dunifon, R. E. (2006) State-Level Predictors of Food Insecurity Among Households with Children. Journal of Policy Analysis and Management, 25(4), 921-42.

Bickel, G., Nord, M., Price, C., Hamilton, W., \& Cook, J. (2000). Guide to Measuring Household Food Security Revised 2000. VA: USDA, FNS.

Blank, R. (1997). It Takes A Nation: A New Agenda for Fighting Poverty. Princeton, NJ: Princeton University Press.

Bronfenbrenner, U., \& Morris, P. (1998). The Ecology of Developmental Processes. In W. Damon \& R. M. Lerner (Eds.), Handbook of Child Psychology: Volume 1 Theoretical Models of Human Development (5 ${ }^{\text {th }}$ ed., pp. 993-1028). NY: Wiley.

Bronte-Tinkew, J., Zaslow, M., Capps, R., Horowitz, A., \& McNamara, M. (2007). Food Insecurity Works through Depression, Parenting, and Infant Feeding to Influence Overweight and Health in Toddlers. Journal of Nutrition, 137, 2160-65.

Chen, W., \& Corak, M. (2008). Child Poverty and Changes in Child Poverty. Demography, 45(3), 537-553.

Coleman-Jensen, A., Nord, M., Andrews, M., \& Carlson, S. (2012). Household Food Security in the United States in 2011. DC: USDA, ERS, ERR-141.

Cook, J. T., Frank, D. A., Berkowitz, C., Black, M. M., Casey, P. H., Cutts, D. B., Meyers, A. F., Zaldivar, N., Skalicky, A., Levenson, S., Heeren, T., \& Nord, M. (2004). Food Insecurity is Associated with Adverse Health Outcomes Among Human Infants and Toddlers. American Society for Nutritional Sciences, 134, 1432-1438. 
Cook, J. T., Frank, D. A., Levenson, S. M., Neault, N. B., Heeren, T. C., Black, M. M., Berkowitz, C., Casey, P. H., Meyers, A. F., Cutts, D. B., \& Chilton, M. (2006). Child Food Insecurity Increases Risks Posed by Household Food Insecurity to Young Children’s Health. American Society for Nutrition, 136 (4), 1073-1076.

Cummings, E. M., \& Davies, P. T. (1994). Maternal depression and child development. Journal of Child Psychology and Psychiatry, 35(1), 73-122.

Grace, S, Evindar, A. \& Stewart, D. (2003). The effect of postpartum depression on child cognitive development and behavior: A review and critical analysis of the literature. Archives of Women's Mental Health, 6, 263-74.

Gundersen, C., \& Gruber, J. (2001). Dynamic Determinants of Food Insufficiency. Second Food Security Measurement and Research Conference, Volume II: Papers. DC: USDA, ERS, Food Assistance and Nutrition Research Report No. 11-12.

Gundersen, C., Lohman, B. J., Garasky, S., Stewart, S., \& Eisenmann, J. (2008). Food security, maternal stressors, and overweight among low-income US children: Results from the National Health and Nutrition Examination Survey (1999-2002). Pediatrics, 122(3), e529-e540.

Hay, D. F., Pawlby, S., Angold, A., Harold, G. T., \& Sharp, D. (2003). Pathways to violence in the children of mothers who were depressed postpartum. Developmental Psychology, 39(6), 1083-1094.

Heflin, C., \& J.S. Butler. (In press). “Why Do Women Enter and Exit from Material Hardship?” Journal of Family Issues.

Heflin, C., \& J.P. Ziliak. (2008). “Food Insufficiency, Food Stamp Participation, and Mental Health.” Social Science Quarterly, 8(3), 706-727. 
Huddleston-Casas, C., Charnigo, R., \& Simmons, L.A. (2009). "Food Insecurity and Maternal Depression in Rural, Low-Income Families: A Longitudinal Investigation”. Public Health Nutrition, 12(8), 1133-1140.

Kessler, R., Barker, P. R., Colpe, L. J., et al. (2003). Screening for serious mental illness in the general population. Archives of General Psychiatry, 60, 184-189.

Laraia, B., Siega-Riz, A., Gundersen, C. \& Dole, N. (2006). “Psychosocial Factors and Socioeconomic Indicators are Associated with Household Food Insecurity among Pregnant Women.” The Journal of Nutrition, 136(1), 177-182.

Lichter, D. T., Qian, Z., \& Melliot, L. M. (2006). Marriage or Dissolution? Union Transitions Among Poor Cohabitating Women. Demography, 43(2), 223-240.

Nord, M. (2009) Food Insecurity in Households with Children. DC: USDA, ERS, EIBN-56.

Nord, M. \& Bickel, G. (2002). Measuring Children’s Food Security in U.S. Households, 199599. DC: USDA, ERS, FANRR25.

Nord, M., \& Brent, C. P. (2002). Food Insecurity in Higher Income Households. USDA ERS report.

Nord, M., \& Parker, L. (2010). How adequately are food needs of children in low-income households being met? Children and Youth Services Review, 32, 1175-1185

Ohls, J., Radbill, L., \& Schirm, A. (2001). Household Food Security in the United States, 19951997: Technical Issues and Statistical Report. VA: USDA, FNS.

Radloff, L. S. (1977). The CES-D: A self-report depression scale for research in the general population. Applied Psychological Measurement, 1, 385-401.

Shonkoff, J.P., \& Phillips, D.A. (Eds.) Committee on Integrating the Science of Early Childhood Development, Board on Children, Youth, and Families. (2000). From Neurons to 
Neighborhoods: The Science of Early Childhood Programs. DC: National Academy Press.

Skalicky, A., Meyers, A. F., Adams, W. G., Yang, Z., Cook, J. T., \& Frank, D. A. (2006). Child Food Insecurity and Iron Deficiency Anemia in Low-Income Infants and Toddlers in the United States. Maternal and Child Health Journal, 10 (2), 177-185.

Tapogna, J., Suter, A., Nord, M., \& Leachman, M. (2004). Explaining Variations in State Hunger Rates. Family Economics and Nutrition Review, 16(2), 12.

Whitaker, R. C., Phillips, S. M., \& Orzol, S. M. (2006). Food Insecurity and Risks of Depression and Anxiety in Mothers and Behavior Problems in Their Preschool-Aged Children. Pediatrics, 118 (3), e859-e868.

Wunderlich, G.S., \& Norwood, J.L. (2006). Food Insecurity and Hunger in the United States: An Assessment of the Measure. DC: The National Academies Press. 


\section{GRAPHS AND TABLES}

\section{Graph 1. Percentage of Transitions Entering and Exiting Food Insecurity}

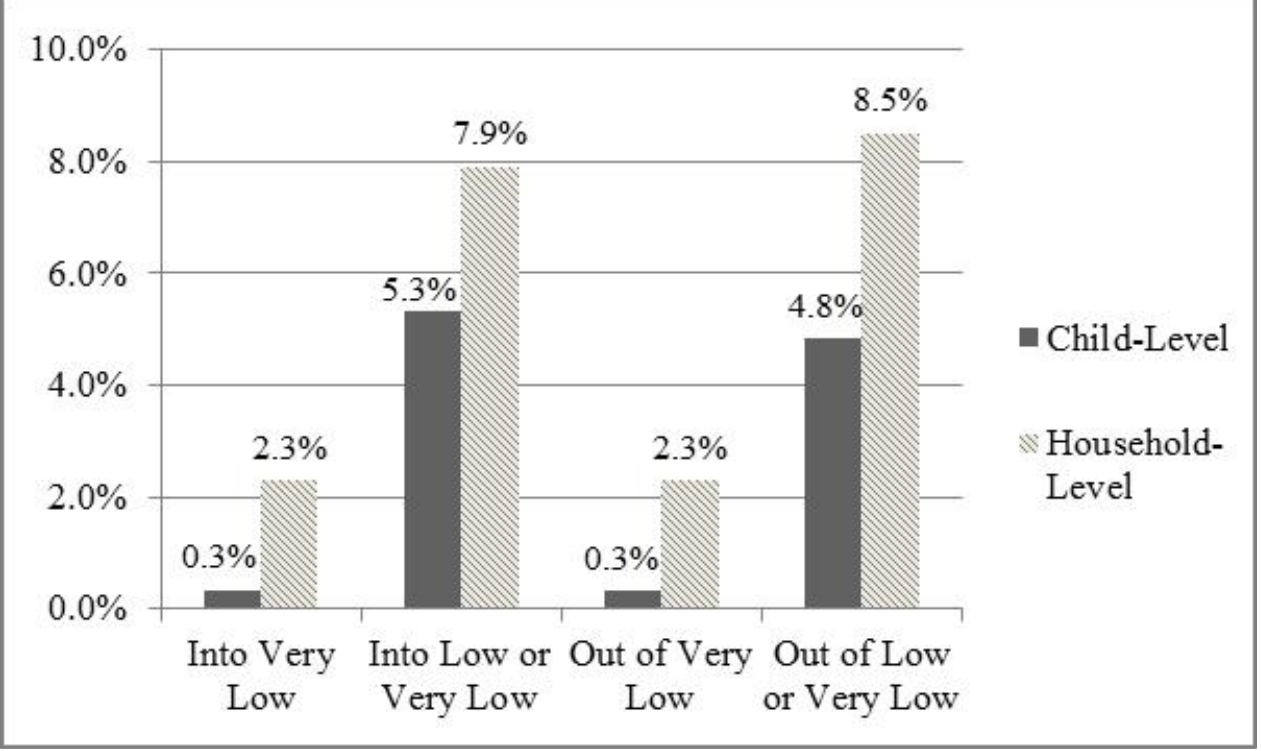

Note: Sample size is 18,950 transitions. 
Table 1. Description of Transitions

\% of All Transitions

Predictors of Entry into and Exit from Food Insecurity

Change of Residence $\quad 41.4 \%$

Mother Became Unemployed $\quad 10.0 \%$

Mother Became Unemployed- Out of Labor Force $\quad 6.9 \%$

Mother Became Unemployed- In Labor Force $\quad 3.1 \%$

Mother Became Employed $\quad 15.0 \%$

Decrease in \# of Adults $\quad 15.2 \%$

Increase in \# of Adults $\quad 12.3 \%$

Increase in \# of Children $\quad 18.1 \%$

Decrease in \# of Children $\quad 8.2 \%$

Income Decreases $\quad 31.1 \%$

Income Increases $\quad 43.8 \%$

Child Health Worsens $\quad 24.4 \%$

Child Health Improves $\quad 22.1 \%$

Mother Health Worsens $\quad 29.0 \%$

Mother Health Improves $\quad 24.2 \%$

Mother Enters Depression $\quad 11.7 \%$

Mother Exits Depression $\quad 11.6 \%$

Other Predictors of Food Insecurity Transition

Multiple-Order Birth $\quad 15.4 \%$

$\begin{array}{ll}\text { Child is Female } & 49.5 \%\end{array}$

Child Race: non-Hispanic White $\quad 36.8 \%$

Child Race: non-Hispanic Black $\quad 19.2 \%$

Child Race: Hispanic $\quad 24.0 \%$

Child Race: Other $\quad 20.0 \%$

Transition 1: Between 9-month and 2-year Interview $\quad 38.3 \%$

Transition 2: Between 2-year and 4-year Interview $\quad 34.5 \%$

Transition 3: Between 4-year and 5-year Interview $\quad 27.2 \%$

$\begin{array}{lc}\text { Sample size } & 18,950\end{array}$ 
Table 2A. Descriptive Statistics on Predictors of Entry into Food Insecurity

\begin{tabular}{lcccc}
\hline & \multicolumn{2}{c}{ Child Level } & \multicolumn{2}{c}{ Household Level } \\
& $\begin{array}{c}\text { Into } \\
\text { Very } \\
\text { Predictors of Entry }\end{array}$ & $\begin{array}{c}\text { Into Low } \\
\text { or Very } \\
\text { Low }\end{array}$ & $\begin{array}{c}\text { Into Very } \\
\text { Low }\end{array}$ & $\begin{array}{c}\text { or Very } \\
\text { Low }\end{array}$ \\
\hline Mother Became Unemployed & $12.7 \%$ & $12.3 \%$ & $13.3 \%$ & $12.9 \%$ \\
$\quad$ Mother Became Unemployed- Out of Labor Force & $9.5 \%$ & $7.9 \%$ & $8.5 \%$ & $7.3 \%$ \\
$\quad$ Mother Became Unemployed- In Labor Force & $3.2 \%$ & $4.4 \%$ & $4.8 \%$ & $5.6 \%$ \\
Decrease in \# of Adults & $19.1 \%$ & $20.4 \%$ & $21.7 \%$ & $21.6 \%$ \\
Increase in \# of Children & $14.3 \%$ & $21.5 \%$ & $19.9 \%$ & $20.2 \%$ \\
Income Decreases & $42.9 \%$ & $41.8 \%$ & $47.6 \%$ & $43.7 \%$ \\
Child Health Worsens & $31.8 \%$ & $29.7 \%$ & $30.4 \%$ & $29.1 \%$ \\
Mother Health Worsens & $44.4 \%$ & $33.7 \%$ & $40.7 \%$ & $31.4 \%$ \\
Mother Enters Depression & $27.0 \%$ & $22.0 \%$ & $28.4 \%$ & $22.2 \%$ \\
Change of Residence & $57.1 \%$ & $50.3 \%$ & $59.0 \%$ & $51.5 \%$ \\
\hline Sample size & 50 & 1,000 & 450 & 1,500 \\
\hline
\end{tabular}


Table 2B. Descriptive Statistics on Predictors of Exit from Food Insecurity

\begin{tabular}{lcccc}
\hline & \multicolumn{2}{c}{ Child Level } & \multicolumn{2}{c}{ Household Level } \\
Predictors of Exit & $\begin{array}{c}\text { Out of Very } \\
\text { Low }\end{array}$ & $\begin{array}{c}\text { Out of Low or } \\
\text { Very Low }\end{array}$ & $\begin{array}{c}\text { Out of Very } \\
\text { Low }\end{array}$ & $\begin{array}{c}\text { Out of Low or } \\
\text { Very Low }\end{array}$ \\
\hline Mother Became Employed & $15.5 \%$ & $16.6 \%$ & $18.7 \%$ & $17.2 \%$ \\
Increase in \# of Adults & $31.0 \%$ & $18.3 \%$ & $21.4 \%$ & $17.8 \%$ \\
Decrease in \# of Children & $10.3 \%$ & $11.0 \%$ & $12.9 \%$ & $10.3 \%$ \\
Income Increases & $43.1 \%$ & $52.4 \%$ & $53.2 \%$ & $52.8 \%$ \\
Child Health Improves & $32.8 \%$ & $26.3 \%$ & $29.0 \%$ & $25.6 \%$ \\
Mother Health Improves & $32.8 \%$ & $28.9 \%$ & $32.0 \%$ & $28.3 \%$ \\
Mother Exits Depression & $13.8 \%$ & $19.5 \%$ & $22.4 \%$ & $20.1 \%$ \\
Change of Residence & $55.2 \%$ & $46.1 \%$ & $51.8 \%$ & $46.9 \%$ \\
\hline Sample size & 50 & 900 & 450 & 1,600 \\
\hline
\end{tabular}


Table 3. Results from Linear Probability Models Predicting Entry into Food Insecurity

\begin{tabular}{|c|c|c|c|c|}
\hline \multirow[b]{2}{*}{ Variables } & \multicolumn{2}{|c|}{ Child Level } & \multicolumn{2}{|c|}{ Household Level } \\
\hline & $\begin{array}{l}\text { Into Very } \\
\text { Low }\end{array}$ & $\begin{array}{l}\text { Into Low or } \\
\text { Very Low }\end{array}$ & $\begin{array}{l}\text { Into Very } \\
\text { Low }\end{array}$ & $\begin{array}{l}\text { Into Low or } \\
\text { Very Low }\end{array}$ \\
\hline $\begin{array}{l}\text { Mother Became Unemployed- Out of } \\
\text { Labor Force }\end{array}$ & $\begin{array}{c}0.001 \\
(0.002)\end{array}$ & $\begin{array}{c}0.004 \\
(0.007)\end{array}$ & $\begin{array}{c}0.002 \\
(0.005)\end{array}$ & $\begin{array}{l}-0.003 \\
(0.009)\end{array}$ \\
\hline $\begin{array}{l}\text { Mother Became Unemployed- In Labor } \\
\text { Force }\end{array}$ & $\begin{array}{l}-0.001 \\
(0.002)\end{array}$ & $\begin{array}{c}0.015 \\
(0.012)\end{array}$ & $\begin{array}{c}0.008 \\
(0.008)\end{array}$ & $\begin{array}{c}0.064 * * * \\
(0.017)\end{array}$ \\
\hline Decrease in \# of Adults & $\begin{array}{l}-0.000 \\
(0.001)\end{array}$ & $\begin{array}{c}0.009 \\
(0.006)\end{array}$ & $\begin{array}{c}0.002 \\
(0.004)\end{array}$ & $\begin{array}{l}0.021^{* * *} \\
(0.008)\end{array}$ \\
\hline Increase in \# of Children & $\begin{array}{l}-0.002 \\
(0.001)\end{array}$ & $\begin{array}{l}0.006 \\
(0.005)\end{array}$ & $\begin{array}{l}-0.001 \\
(0.003)\end{array}$ & $\begin{array}{c}0.003 \\
(0.006)\end{array}$ \\
\hline Income Decreases & $\begin{array}{c}0.002 \\
(0.001)\end{array}$ & $\begin{array}{c}0.022 * * * \\
(0.004)\end{array}$ & $\begin{array}{c}0.016^{* * *} \\
(0.003)\end{array}$ & $\begin{array}{c}0.042 * * * \\
(0.005)\end{array}$ \\
\hline Child Health Worsens & $\begin{array}{c}0.001 \\
(0.001)\end{array}$ & $\begin{array}{c}0.010^{* *} \\
(0.004)\end{array}$ & $\begin{array}{c}0.004 \\
(0.003)\end{array}$ & $\begin{array}{c}0.017 * * * \\
(0.006)\end{array}$ \\
\hline Mother Health Worsens & $\begin{array}{l}0.002^{*} \\
(0.001)\end{array}$ & $\begin{array}{l}0.007 \\
(0.004)\end{array}$ & $\begin{array}{c}0.010^{* * *} \\
(0.003)\end{array}$ & $\begin{array}{c}0.000 \\
(0.005)\end{array}$ \\
\hline Mother Enters Depression & $\begin{array}{c}0.005^{* *} \\
(0.002)\end{array}$ & $\begin{array}{c}0.054 * * * \\
(0.007)\end{array}$ & $\begin{array}{c}0.036 * * * \\
(0.005)\end{array}$ & $\begin{array}{c}0.092 * * * \\
(0.009)\end{array}$ \\
\hline Change of Residence & $\begin{array}{l}0.002^{*} \\
(0.001)\end{array}$ & $\begin{array}{c}0.012 * * * \\
(0.004)\end{array}$ & $\begin{array}{c}0.014^{* * *} \\
(0.003)\end{array}$ & $\begin{array}{c}0.026 * * * \\
(0.005)\end{array}$ \\
\hline Multiple-Order Birth & $\begin{array}{c}-0.002^{* *} \\
(0.001)\end{array}$ & $\begin{array}{l}0.008 \\
(0.005)\end{array}$ & $\begin{array}{l}0.006^{*} \\
(0.003)\end{array}$ & $\begin{array}{c}0.000 \\
(0.006)\end{array}$ \\
\hline Child is Female & $\begin{array}{l}-0.000 \\
(0.001)\end{array}$ & $\begin{array}{l}-0.001 \\
(0.004)\end{array}$ & $\begin{array}{c}0.002 \\
(0.002)\end{array}$ & $\begin{array}{l}-0.005 \\
(0.005)\end{array}$ \\
\hline Child Race: non-Hispanic Black & $\begin{array}{l}0.002^{*} \\
(0.001)\end{array}$ & $\begin{array}{c}0.029 * * * \\
(0.005)\end{array}$ & $\begin{array}{c}0.009 * * * \\
(0.003)\end{array}$ & $\begin{array}{c}0.027 * * * \\
(0.007)\end{array}$ \\
\hline Child Race: Hispanic & $\begin{array}{l}0.002^{*} \\
(0.001)\end{array}$ & $\begin{array}{c}0.032 * * * \\
(0.005)\end{array}$ & $\begin{array}{l}0.005^{*} \\
(0.003)\end{array}$ & $\begin{array}{c}0.023 * * * \\
(0.006)\end{array}$ \\
\hline Child Race: Other & $\begin{array}{c}0.001 \\
(0.001)\end{array}$ & $\begin{array}{c}0.020 * * * \\
(0.005)\end{array}$ & $\begin{array}{l}0.006^{* *} \\
(0.003)\end{array}$ & $\begin{array}{c}0.017 * * * \\
(0.006)\end{array}$ \\
\hline $\begin{array}{l}\text { Transition 1: Between 9-month and 2- } \\
\text { year Interview }\end{array}$ & $\begin{array}{l}-0.001 \\
(0.001)\end{array}$ & $\begin{array}{c}-0.012 * * * \\
(0.004)\end{array}$ & $\begin{array}{c}-0.008 * * * \\
(0.002)\end{array}$ & $\begin{array}{l}-0.002 \\
(0.005)\end{array}$ \\
\hline $\begin{array}{l}\text { Transition 2: Between 2-year and 4-year } \\
\text { Interview }\end{array}$ & $\begin{array}{c}0.001 \\
(0.001)\end{array}$ & $\begin{array}{c}0.023^{* * *} \\
(0.005)\end{array}$ & $\begin{array}{c}0.008 * * \\
(0.003)\end{array}$ & $\begin{array}{c}0.041^{* * *} \\
(0.006)\end{array}$ \\
\hline Constant & $\begin{array}{c}0.001 \\
(0.001)\end{array}$ & $\begin{array}{c}0.009 * * \\
(0.004)\end{array}$ & $\begin{array}{c}-0.001 \\
(0.003)\end{array}$ & $\begin{array}{c}0.021 * * * \\
(0.006)\end{array}$ \\
\hline Sample size & 18,900 & 17,550 & 18,350 & 16,150 \\
\hline
\end{tabular}

$* * * \mathrm{p}<0.01, * * \mathrm{p}<0.05, * \mathrm{p}<0.1$

Notes: Robust standard errors are in parentheses. Reference groups for independent variables: became employed \& job status stayed the same, increase in \# of adults \& \# of adults stayed the same, decrease in \# of children \& \# of children stayed the same, income increases \& income stayed the same, child health improves \& child health stays the same, mother health improves \& mother health stays the same, mother exits depression \& maternal depression status stays the same, child race: non-Hispanic White, transition 3: between 4-year and 5-year interview. 
Table 4. Results from Linear Probability Models Predicting Exit out of Food Insecurity

\begin{tabular}{|c|c|c|c|c|}
\hline Variables & $\begin{array}{c}\text { Out of Very } \\
\text { Low }\end{array}$ & $\begin{array}{l}\frac{\text { evel }}{\text { Out of Low }} \\
\text { or Very } \\
\text { Low }\end{array}$ & $\begin{array}{c}\text { Out of } \\
\text { Very Low }\end{array}$ & $\begin{array}{l}\text { Out Level } \\
\text { or Very } \\
\text { Low }\end{array}$ \\
\hline Mother Became Employed & $\begin{array}{c}-0.094 \\
(0.149)\end{array}$ & $\begin{array}{c}0.030 \\
(0.034)\end{array}$ & $\begin{array}{c}0.105^{* *} \\
(0.043)\end{array}$ & $\begin{array}{c}0.040 \\
(0.025)\end{array}$ \\
\hline Increase in \# of Adults & $\begin{array}{c}0.039 \\
(0.108)\end{array}$ & $\begin{array}{l}0.064^{*} \\
(0.033)\end{array}$ & $\begin{array}{c}0.113^{* * *} \\
(0.043)\end{array}$ & $\begin{array}{c}0.067 * * * \\
(0.025)\end{array}$ \\
\hline Decrease in \# of Children & $\begin{array}{l}0.154 * \\
(0.077)\end{array}$ & $\begin{array}{c}0.025 \\
(0.042)\end{array}$ & $\begin{array}{c}0.073 \\
(0.054)\end{array}$ & $\begin{array}{c}0.032 \\
(0.030)\end{array}$ \\
\hline Income Increases & $\begin{array}{c}0.163 \\
(0.113)\end{array}$ & $\begin{array}{c}0.119 * * * \\
(0.025)\end{array}$ & $\begin{array}{c}0.091 * * \\
(0.036)\end{array}$ & $\begin{array}{c}0.112 * * * \\
(0.018)\end{array}$ \\
\hline Child Health Improves & $\begin{array}{c}-0.005 \\
(0.107)\end{array}$ & $\begin{array}{l}-0.007 \\
(0.028)\end{array}$ & $\begin{array}{c}0.074 * \\
(0.040)\end{array}$ & $\begin{array}{l}-0.016 \\
(0.021)\end{array}$ \\
\hline Mother Health Improves & $\begin{array}{c}0.061 \\
(0.089)\end{array}$ & $\begin{array}{c}0.025 \\
(0.028)\end{array}$ & $\begin{array}{c}0.063^{*} \\
(0.038)\end{array}$ & $\begin{array}{l}-0.006 \\
(0.020)\end{array}$ \\
\hline Mother Exits Depression & $\begin{array}{c}0.111 \\
(0.166)\end{array}$ & $\begin{array}{c}0.124^{* * *} \\
(0.033)\end{array}$ & $\begin{array}{c}0.105^{* *} \\
(0.043)\end{array}$ & $\begin{array}{c}0.096 * * * \\
(0.024)\end{array}$ \\
\hline Change of Residence & $\begin{array}{c}-0.064 \\
(0.095)\end{array}$ & $\begin{array}{c}-0.045^{*} \\
(0.026)\end{array}$ & $\begin{array}{l}-0.029 \\
(0.037)\end{array}$ & $\begin{array}{l}-0.025 \\
(0.019)\end{array}$ \\
\hline Multiple-Order Birth & $\begin{array}{c}0.246 \\
(0.178)\end{array}$ & $\begin{array}{l}-0.014 \\
(0.037)\end{array}$ & $\begin{array}{c}0.051 \\
(0.046)\end{array}$ & $\begin{array}{c}-0.015 \\
(0.027)\end{array}$ \\
\hline Child is Female & $\begin{array}{c}-0.143 \\
(0.111)\end{array}$ & $\begin{array}{l}-0.035 \\
(0.027)\end{array}$ & $\begin{array}{l}0.064 * \\
(0.037)\end{array}$ & $\begin{array}{c}0.008 \\
(0.020)\end{array}$ \\
\hline Child Race: non-Hispanic Black & $\begin{array}{c}0.084 \\
(0.117)\end{array}$ & $\begin{array}{c}-0.108^{* * *} \\
(0.039)\end{array}$ & $\begin{array}{l}-0.008 \\
(0.052)\end{array}$ & $\begin{array}{c}-0.088 * * * \\
(0.028)\end{array}$ \\
\hline Child Race: Hispanic & $\begin{array}{l}-0.131 \\
(0.148)\end{array}$ & $\begin{array}{c}-0.106^{* * *} \\
(0.036)\end{array}$ & $\begin{array}{c}0.023 \\
(0.055)\end{array}$ & $\begin{array}{c}-0.111^{* * *} \\
(0.026)\end{array}$ \\
\hline Child Race: Other & $\begin{array}{c}-0.082 \\
(0.179)\end{array}$ & $\begin{array}{l}-0.030 \\
(0.037)\end{array}$ & $\begin{array}{c}0.064 \\
(0.051)\end{array}$ & $\begin{array}{c}-0.061^{* *} \\
(0.029)\end{array}$ \\
\hline $\begin{array}{l}\text { Transition 1: Between 9-month and 2- } \\
\quad \text { year Interview }\end{array}$ & $\begin{array}{c}0.072 \\
(0.142)\end{array}$ & $\begin{array}{c}0.129 * * * \\
(0.028)\end{array}$ & $\begin{array}{c}0.107 * * * \\
(0.040)\end{array}$ & $\begin{array}{c}0.137 * * * \\
(0.021)\end{array}$ \\
\hline $\begin{array}{l}\text { Transition 2: Between 2-year and 4- } \\
\text { year Interview }\end{array}$ & $\begin{array}{c}0.014 \\
(0.137)\end{array}$ & $\begin{array}{c}0.014 \\
(0.032)\end{array}$ & $\begin{array}{c}0.029 \\
(0.049)\end{array}$ & $\begin{array}{c}0.017 \\
(0.023)\end{array}$ \\
\hline Constant & $\begin{array}{c}0.843 * * * \\
(0.205)\end{array}$ & $\begin{array}{c}0.595 * * * \\
(0.043)\end{array}$ & $\begin{array}{c}0.466 * * * \\
(0.065)\end{array}$ & $\begin{array}{c}0.489 * * * \\
(0.031)\end{array}$ \\
\hline Sample size & 50 & 1,400 & 600 & 2,800 \\
\hline
\end{tabular}

Notes: Robust standard errors are in parentheses. Reference groups for independent variables: became unemployed \& job status stayed the same, decrease in \# of adults \& \# of adults stayed the same, increase in \# of children \& \# of children stayed the same, income decreases \& income stayed the same, child health worsens \& child health stays the same, mother health worsens \& mother health stays the same, mother enters depression \& maternal depression status stays the same, child race: non-Hispanic White, transition 3: between 4-year and 5-year interview. 
Table 5. Results from OLS Models Examining Food Insecurity Raw Scores

\begin{tabular}{|c|c|c|}
\hline Variables & $\begin{array}{c}\text { Difference in Child-level } \\
\text { Raw Score }\end{array}$ & $\begin{array}{l}\text { Difference in Household- } \\
\text { level Raw Score }\end{array}$ \\
\hline Mother Became Employed & $\begin{array}{l}-0.008 \\
(0.019)\end{array}$ & $\begin{array}{c}-0.042 \\
(0.054)\end{array}$ \\
\hline $\begin{array}{l}\text { Mother Became Unemployed- } \\
\text { Out of Labor Force }\end{array}$ & $\begin{array}{c}0.020 \\
(0.026)\end{array}$ & $\begin{array}{c}0.049 \\
(0.074)\end{array}$ \\
\hline $\begin{array}{l}\text { Mother Became Unemployed- In } \\
\text { Labor Force }\end{array}$ & $\begin{array}{l}0.102 * * \\
(0.040)\end{array}$ & $\begin{array}{l}0.262 * * \\
(0.116)\end{array}$ \\
\hline Increase in \# of Adults & $\begin{array}{c}-0.054 * * \\
(0.024)\end{array}$ & $\begin{array}{c}-0.184^{* * *} \\
(0.066)\end{array}$ \\
\hline Decrease in \# of Adults & $\begin{array}{c}0.021 \\
(0.020)\end{array}$ & $\begin{array}{c}0.045 \\
(0.057)\end{array}$ \\
\hline Increase in \# of Children & $\begin{array}{c}0.013 \\
(0.017)\end{array}$ & $\begin{array}{l}-0.013 \\
(0.047)\end{array}$ \\
\hline Decrease in \# of Children & $\begin{array}{l}-0.043 \\
(0.027)\end{array}$ & $\begin{array}{l}-0.037 \\
(0.079)\end{array}$ \\
\hline Income Increases & $\begin{array}{c}-0.069 * * * \\
(0.015)\end{array}$ & $\begin{array}{l}-0.272 * * * \\
(0.042)\end{array}$ \\
\hline Income Decreases & $\begin{array}{c}0.069 * * * \\
(0.017)\end{array}$ & $\begin{array}{c}0.287 * * * \\
(0.046)\end{array}$ \\
\hline Child Health Improves & $\begin{array}{c}-0.040 * * \\
(0.017)\end{array}$ & $\begin{array}{l}-0.130 * * * \\
(0.046)\end{array}$ \\
\hline Child Health Worsens & $\begin{array}{l}-0.006 \\
(0.017)\end{array}$ & $\begin{array}{l}-0.008 \\
(0.046)\end{array}$ \\
\hline Mother Health Improves & $\begin{array}{l}-0.026 \\
(0.017)\end{array}$ & $\begin{array}{c}-0.117^{* *} \\
(0.045)\end{array}$ \\
\hline Mother Health Worsens & $\begin{array}{c}0.017 \\
(0.016)\end{array}$ & $\begin{array}{c}0.064 \\
(0.044)\end{array}$ \\
\hline Mother Exits Depression & $\begin{array}{c}0.154^{* * *} \\
(0.023)\end{array}$ & $\begin{array}{c}0.540 * * * \\
(0.065)\end{array}$ \\
\hline Mother Enters Depression & $\begin{array}{l}-0.122 * * * \\
(0.022)\end{array}$ & $\begin{array}{l}-0.447 * * * \\
(0.064)\end{array}$ \\
\hline Change of Residence & $\begin{array}{c}0.017 \\
(0.013)\end{array}$ & $\begin{array}{l}0.028 \\
(0.036)\end{array}$ \\
\hline $\begin{array}{l}\text { FS Score Moved Zero-to-One or } \\
\text { One-to-Zero }\end{array}$ & $\begin{array}{c}0.007 \\
(0.016)\end{array}$ & $\begin{array}{l}-0.027 \\
(0.022)\end{array}$ \\
\hline Multiple-Order Birth & $\begin{array}{c}0.007 \\
(0.011)\end{array}$ & $\begin{array}{l}-0.001 \\
(0.033)\end{array}$ \\
\hline Child is Female & $\begin{array}{c}0.008 \\
(0.008)\end{array}$ & $\begin{array}{c}0.015 \\
(0.024)\end{array}$ \\
\hline Child Race: non-Hispanic Black & $\begin{array}{c}0.014 \\
(0.012)\end{array}$ & $\begin{array}{c}0.022 \\
(0.036)\end{array}$ \\
\hline Child Race: Hispanic & $\begin{array}{c}-0.002 \\
(0.012)\end{array}$ & $\begin{array}{c}0.005 \\
(0.033)\end{array}$ \\
\hline Child Race: Other & $\begin{array}{c}0.016 \\
(0.012)\end{array}$ & $\begin{array}{c}0.041 \\
(0.033)\end{array}$ \\
\hline
\end{tabular}


Table 5. Results from OLS Models Examining Food Insecurity Raw Scores (continued)

\begin{tabular}{|c|c|c|}
\hline Variables & $\begin{array}{c}\text { Difference in } \\
\text { Child-level Raw } \\
\text { Score }\end{array}$ & $\begin{array}{c}\text { Difference in } \\
\text { Household-level } \\
\text { Raw Score }\end{array}$ \\
\hline Transition 1: Between 9-month and 2-year Interview & $\begin{array}{c}-0.006 \\
(0.015) \\
0.154 * * *\end{array}$ & $\begin{array}{c}-0.123^{* * *} \\
(0.043) \\
0.490 * * *\end{array}$ \\
\hline Transition 2: Between 2-year and 4-year Interview & $\begin{array}{c}(0.020) \\
-0.036 * *\end{array}$ & $\begin{array}{c}(0.053) \\
-0.122 * * *\end{array}$ \\
\hline Constant & $(0.017)$ & $(0.047)$ \\
\hline Sample size & 18,950 & 18,950 \\
\hline
\end{tabular}

Notes: Robust standard errors are in parentheses. Reference groups for independent variables: job status stayed the same, \# of adults stayed the same, \# of children stayed the same, income stayed the same, child health stays the same, mother health stays the same, maternal depression status stays the same, child race: non-Hispanic White, transition 3: between 4-year and 5-year interview. 
Appendix Table 1: Variable Definitions

\begin{tabular}{|c|c|}
\hline Variable Name & Variable Definition \\
\hline \multicolumn{2}{|l|}{ Dependent Variables } \\
\hline $\begin{array}{l}\text { Child Level: Entered } \\
\text { Very Low Food Security }\end{array}$ & $\begin{array}{l}1 \text { = Respondent reports child-level food security or low food security in } \\
\text { previous wave and very low food security in current wave } \\
0=\text { Respondent reports child-level food security or low food security in both } \\
\text { the previous and current waves }\end{array}$ \\
\hline $\begin{array}{l}\text { Child Level: Exited Very } \\
\text { Low Food Security }\end{array}$ & $\begin{array}{l}1=\text { Respondent reports very low child-level food security in previous wave } \\
\text { and food security or low food security in current wave } \\
0=\text { Respondent reports very low child-level food security in both the current } \\
\text { and previous waves }\end{array}$ \\
\hline $\begin{array}{l}\text { Child Level: Entered Low } \\
\text { or Very Low Food } \\
\text { Security }\end{array}$ & $\begin{array}{l}1=\text { Respondent reports child-level food security in previous wave and low or } \\
\text { very low food security in current wave } \\
0=\text { Respondent reports child-level food security in both the previous wave } \\
\text { and current waves }\end{array}$ \\
\hline $\begin{array}{l}\text { Child Level: Exited Low } \\
\text { or Very Low Food } \\
\text { Security }\end{array}$ & $\begin{array}{l}1=\text { Respondent reports low or very low child-level food security in previous } \\
\text { wave and food security in current wave } \\
0=\text { Respondent reports child-level low or very low food security in both the } \\
\text { previous wave and current waves }\end{array}$ \\
\hline $\begin{array}{l}\text { Household Level: Entered } \\
\text { Very Low Food Security }\end{array}$ & $\begin{array}{l}1 \text { = Respondent reports household-level food security or low food security in } \\
\text { previous wave and very low food security in current wave } \\
0=\text { Respondent reports household-level food security or low food security in } \\
\text { both the previous wave and current waves }\end{array}$ \\
\hline $\begin{array}{l}\text { Household Level: Exited } \\
\text { Very Low Food Security }\end{array}$ & $\begin{array}{l}1=\text { Respondent reports very low household-level food security in previous } \\
\text { wave and food security or low food security in current wave } \\
0=\text { Respondent reports household-level very low food security in both the } \\
\text { previous wave and current waves }\end{array}$ \\
\hline $\begin{array}{l}\text { Household Level: Entered } \\
\text { Low or Very Low Food } \\
\text { Security }\end{array}$ & $\begin{array}{l}1=\text { Respondent reports household-level food security in previous wave and } \\
\text { low or very low food security in current wave } \\
0=\text { Respondent reports household-level food security in both the previous } \\
\text { wave and current waves }\end{array}$ \\
\hline $\begin{array}{l}\text { Household Level: Exited } \\
\text { Low or Very Low Food } \\
\text { Security }\end{array}$ & $\begin{array}{l}1=\text { Respondent reports low or very low household-level food security in } \\
\text { previous wave and food security in current wave } \\
0=\text { Respondent reports household-level very low food security in both the } \\
\text { previous wave and current waves }\end{array}$ \\
\hline \multicolumn{2}{|l|}{ Predictors } \\
\hline $\begin{array}{l}\text { Mother Became } \\
\text { Employed }\end{array}$ & $\begin{array}{l}1=\text { Mother had no job in previous wave but has a job (or multiple jobs) in } \\
\text { current wave } \\
0=\text { Mother lost job or job status has not changed since previous wave }\end{array}$ \\
\hline $\begin{array}{l}\text { Mother Became } \\
\text { Unemployed }\end{array}$ & $\begin{array}{l}1 \text { = Mother had a job (or multiple jobs) in previous wave but has no job in } \\
\text { current wave } \\
0=\text { Mother got a job or job status has not changed since previous wave }\end{array}$ \\
\hline Increase in \# of Adults & $\begin{array}{l}1=\text { Number of adults }(18+) \text { in the household has increased since previous } \\
\text { wave } \\
0=\text { Number of adults in the household has decreased or stayed the same since } \\
\text { previous wave }\end{array}$ \\
\hline Decrease in \# of Adults & $\begin{array}{l}1=\text { Number of adults }(18+) \text { in the household has decreased since previous } \\
\text { wave } \\
0=\text { Number of adults in the household has increased or stayed the same since } \\
\text { previous wave }\end{array}$ \\
\hline
\end{tabular}


Appendix Table 1: Variable Definitions (continued)

\begin{tabular}{|c|c|}
\hline Variable Name & Variable Definition \\
\hline Increase in \# of Children & $\begin{array}{l}1=\text { Number of children in the household has increased since previous wave } \\
0=\text { Number of children in the household has decreased or stayed the same } \\
\text { since previous wave }\end{array}$ \\
\hline Decrease in \# of Children & $\begin{array}{l}1=\text { Number of children in the household has decreased since previous wave } \\
0=\text { Number of children in the household has increased or stayed the same } \\
\text { since previous wave }\end{array}$ \\
\hline Income Increases & $\begin{array}{l}1=\text { Household income category has increased since previous wave } \\
0=\text { Household income category has decreased or stayed the same since } \\
\text { previous wave }\end{array}$ \\
\hline Income Decreases & $\begin{array}{l}1=\text { Household income category has decreased since previous wave } \\
0=\text { Household income category has increased or stayed the same since } \\
\text { previous wave }\end{array}$ \\
\hline Mother Health Improves & $\begin{array}{l}1=\text { Mother health status improved since previous wave } \\
0=\text { Mother health status worsened or stayed the same since previous wave }\end{array}$ \\
\hline Mother Health Worsens & $\begin{array}{l}1=\text { Mother health status worsened since previous wave } \\
0=\text { Mother health status improved or stayed the same since previous wave }\end{array}$ \\
\hline Child Health Improves & $\begin{array}{l}1 \text { = Child health status improved since previous wave } \\
0=\text { Child health status worsened or stayed the same since previous wave }\end{array}$ \\
\hline Child Health Worsens & $\begin{array}{l}1=\text { Child health status worsened since previous wave } \\
0=\text { Child health status improved or stayed the same since previous wave }\end{array}$ \\
\hline Mother Exits Depression & $\begin{array}{l}1=\text { Mother exited depression since previous wave } \\
0=\text { Mother entered depression or status stayed the same since previous wave }\end{array}$ \\
\hline Mother Enters Depression & $\begin{array}{l}1=\text { Mother entered depression since previous wave } \\
0=\text { Mother exited depression or status stayed the same since previous wave }\end{array}$ \\
\hline Change of Residence & $\begin{array}{l}1=\text { Respondent has moved since previous wave } \\
0=\text { Respondent has not moved since previous wave }\end{array}$ \\
\hline \multicolumn{2}{|c|}{ Other independent variables } \\
\hline Multiple-Order Birth & $\begin{array}{l}1=\text { Observation is a twin or higher order birth } \\
0=\text { Observation is a single birth }\end{array}$ \\
\hline Child is Female & $\begin{array}{l}1=\text { Child is female } \\
0=\text { Child is male }\end{array}$ \\
\hline $\begin{array}{l}\text { Child Race: non-Hispanic } \\
\text { White }\end{array}$ & $\begin{array}{l}1=\text { Child is non-Hispanic white } \\
0=\text { Child is not non-Hispanic white }\end{array}$ \\
\hline $\begin{array}{l}\text { Child Race: non-Hispanic } \\
\text { Black }\end{array}$ & $\begin{array}{l}1=\text { Child is non-Hispanic black } \\
0=\text { Child is not non-Hispanic black }\end{array}$ \\
\hline Child Race: Hispanic & $\begin{array}{l}1=\text { Child is Hispanic } \\
0=\text { Child is not Hispanic }\end{array}$ \\
\hline Child Race: Other & $\begin{array}{l}1=\text { Child is other race or is multi-racial } \\
0=\text { Child is not other race or multi-racial }\end{array}$ \\
\hline $\begin{array}{l}\text { Transition 1: Between 9- } \\
\text { month and 2-year } \\
\text { Interview }\end{array}$ & $\begin{array}{l}1=\text { Transition } 1 \\
0=\text { Transition } 2 \text { or Transition } 3\end{array}$ \\
\hline $\begin{array}{l}\text { Transition 2: Between 2- } \\
\text { year and 4-year Interview }\end{array}$ & $\begin{array}{l}1=\text { Transition } 2 \\
0=\text { Transition } 1 \text { or Transition } 3\end{array}$ \\
\hline
\end{tabular}

